\title{
MEU CORPO DARIA UM ROMANCE RIZOMÁTICO
}

\section{MY BODY WOULD GIVE A RHIZOMATIC NOVEL}

\author{
José Veranildo Lopes da Costa Junior ${ }^{1}$ \\ Roniê Rodrigues da Silva²
}

\begin{abstract}
RESUMO: Este artigo objetiva realizar uma leitura crítica da narrativa Meu corpo daria um romance (1984), do escritor mineiro Herbert Daniel, cuja trama principal conta a história do protagonista Daniel, que após beijar o seu namorado, em uma parada de ônibus, na praia de Copacabana, no Rio de Janeiro, vivencia, ao longo de onze minutos, uma série de discursos e olhares homofóbicos. Em nossa análise, buscamos aproximar os processos de subjetivaçăo do personagem ao conceito de rizoma, proposto pelos filósofos franceses Gilles Deleuze e Félix Guattari (2011), destacando em nosso exame como Daniel representa um corpo rizomático, enquanto que as cenas protagonizadas pelos demais personagens secundários caracterizam a ideia de organismos tradicionais e sexistas.
\end{abstract}

PALAVRAS-CHAVE: Meu corpo daria um romance. Rizoma. Filosofia. Literatura.

\begin{abstract}
This article aims to make a critical reading about the narrative My body would give a novel (1984), the novel was written by Herbert Daniel, whose main plot tells us the story of the protagonist Daniel, the one, who after kissing his boyfriend at a bus stop on the beach of Copacabana, in Rio de Janeiro, he experiences over eleven minutes, a lot of speeches and homophobic looks. In our analysis, we seek to approximate the processes of subjectivation of the character to the concept of rhizome, proposed by the French philosophers Gilles Deleuze and Félix Guattari (2011), we highlight in our examination how Daniel represents a rhizomatic body, while the scenes carried out by the other secondary characters, giving the idea of traditional and sexist organisms.
\end{abstract}

KEYWORDS: My body would make a romance. Rhizome. Philosophy. Literature.

1 Doutorando no Programa de Pós-Graduaçăo em Letras da Universidade do Estado do Rio Grande do Norte. Contato: jveranildo@hotmail.com

2 Docente permanente do Programa de Pós-Graduaçăo em Letras da Universidade do Estado do Rio Grande do Norte. Doutor em Estudos da Linguagem pela Universidade Federal do Rio Grande do Norte. Bolsista PNPD de Pós-Doutorado no Programa de Pós-Graduaçâo em Literatura e Interculturalidade da Universidade Estadual da Paraíba. Contato: rodrigopinon2014@gmail.com 


\title{
PONTO DE PARTIDA
}

\begin{abstract}
Sabe que o sargento que me dava instruçăo militar, no tempo em que eu era de fazer manobras, de um tipo menos charmoso do que as atuais, urrava que "continência năo se bate", quando alguém usava a expressáo incorreta? Sempre dava o berro, "continência năo se bate", enquanto eu pensava: "mas punheta sim, e é muito melhor".
\end{abstract}

Meu corpo daria um romance. Herbert Daniel, 1984.

Nos últimos dez anos, especialmente, presenciamos uma acentuada produçăo literária de romances que se debruçam sob o período ditatorial no Brasil. Para ilustrar essa constataçấo, poderíamos citar como exemplos concretos uma verdadeira multiplicidade de narrativas produzidas sobre a temática da ditadura, tais como: $\mathrm{K}$ - relato de uma busca (2014) e Você vai voltar pra mim (2014), ambos escritos por Bernardo Kucinski; A resistência (2015), de Julián Fuks, Olho de boto (2015), de Salomáo Laredo; Outros cantos (2016), de Maria Valéria Rezende; e tantos outros romances que ajudam a recontar a história oficial sobre o período sanguinário vivido a partir de 1964, com o início dos anos de autoritarismo em nosso país.

Antes de qualquer adentro específico sobre essa produçăo, é fundamental ressaltar o tăo conhecido "dever de memória", postulado pelo filósofo francês Paul Ricœur (2014, p. 101), entendido como "o dever de fazer justiça, pela lembrança, a um outro que năo a si". Ao nos depararmos com a obra desse pensador, chegaremos à conclusăo de que as sociedades contemporâneas possuem uma espécie de compromisso de memória com o passado e com a sua própria história, de modo que é necessário reelaborar as narrativas do pretérito, a fim de fazer justiça com o passado daqueles que foram torturados, injustiçados e perseguidos.

Assim, a literatura assume o compromisso de reformular a narrativa que acometeu o Brasil a partir de 1964, quando os militares implantaram o período de autoritarismo que derramou sangue de incontáveis vidas e oficializou um clima de hostilidade contra as minorias sexuais. Sommer (2004, p. 23) observa que esse compromisso da ficçâo na reelaboraçâo da realidade é uma obrigaçâo da própria literatura: "Quando a história de um país năo existe, exceto em documentos incompletos e dispersos, em tradiçôes vagas que devem ser reunidas e avaliadas, o método narrativo é obrigatório". Dito com outras palavras, a literatura arquiva as memórias sobre a ditadura (FIGUEIREDO, 2017) tendo como funçăo principal mostrar o outro lado da história que năo foi contado, que foi silenciado em detrimento do discurso oficial criado pela sociedade dominante. Decorrente dessas observaçôes, enfatizamos que uma das funçôes da literatura é, portanto, materializar diversas temporalidades da história que, muitas vezes, se tenta apagar e esquecer.

Além do mais, ao levar em conta o contexto de autoritarismo vigente no Brasil ditatorial, é ético concordar que "o golpe de 1964 foi um atentado à legalidade e à constituiçấo, instaurando um regime de exceçăo, em que as liberdades eram tolhidas por um regime repressor" (FIGUEIREDO, 2017, p. 14). Faz-se também de extrema importância denunciar a opressâo e a tortura que acometeu a vida de crianças, jovens, idosos, 
mulheres e homens durante a ditadura nesse país. Para além desse contexto nefasto, em nossos estudos ${ }^{3}$, buscamos sustentar a ideia de que a comunidade homossexual ${ }^{4}$ foi duplamente oprimida, por suas posiçôes políticas e além do mais, por questôes de gênero e de sexualidade.

Considerando esse contexto de discussâo, a Editora Universitária da Universidade Federal de Sáo Carlos (EdUFSCar) publicou, em 2014, um importante estudo intitulado Ditadura e homossexualidades: repressâo, resistência e a busca pela verdade, de autoria dos historiadores James N. Green e Renan Quinalha. Essa pesquisa é pioneira porque apresenta uma leitura crítica da ditadura sob a ótica dos estudos de gênero, mostrando, de modo panorâmico, algumas das principais narrativas de opressăo vivenciadas pelos grupos sexuais minoritários no Brasil. Nas palavras dos autores:

As forças de segurança, portanto, monitoraram e policiaram a homossexualidade por várias razōes nas décadas após 1964. Seguindo tendências históricas, nacionais e internacionais, ideólogos da segurança nos anos 1960 teorizaram o homossexo como parte de uma série de ameaças degenerativas à segurança nacional anticomunista (GREEN; QUINALHA, 2014, p. 29).

Todavia, é pertinente recordar que a Marcha da Família com Deus e pela Liberdade, ocorrida entre março e junho de 1964, foi uma das principais responsáveis pela derrubada do entăo presidente Joâo Goulart, popularmente conhecido como Jango, por setores ultraconservadores, como a Igreja, os grupos de direita e os empresários. Para os que compuseram a Marcha em questáo, "a homossexualidade foi associada com ameaças ao estado, à sociedade e à segurança nacional" (GREEN; QUINALHA, 2014, p. 29). Dessa forma, percebe-se o rechaço à homossexualidade e a demonizaçăo de práticas homossexuais durante o período ditatorial por setores conservadores que defendiam a chamada família tradicional brasileira.

Nesse interstício, esse texto parte da asserçăo de que é necessário reler o período de autoritarismo no Brasil, tendo como plano de fundo os estudos de gênero, para pensar na perseguiçáo sofrida pela comunidade homossexual. Dessa forma, ao recorrer à filosofia contemporânea de base francesa, especificamente no que tange os estudos de Gilles Deleuze e Félix Guattari (2011), percebemos que àqueles que năo se encaixavam em um binarismo de sexo operante entre masculino e feminino; pênis e vagina; homem e mulher tiveram sua sexualidade reprimida por setores tradicionais da sociedade brasileira, que atuaram naquela época, como organismos tradicionais, rejeitando a ideia da constituiçáo de um corpo rizomático (DELEUZE; GUATTARI, 2011).

Portanto, propomos analisar a literatura produzida pelo escritor mineiro Herbert Daniel, focalizando na crítica ao livro Meu corpo daria um romance, publicado em 1984, pela Editora Rocco. Além de denunciar o clima de opressâo e de preconceito aos

30 primeiro autor desenvolve sob a orientaçăo do segundo autor desse artigo uma tese de doutorado intitulada provisoriamente 'Autoritarismo e homossexualidade: uma leitura deleuze-guattariana de Herbert Daniel, Osvaldo Bazán e Pedro Lemebel', na qual interessa a discussăo sobre as intersecçóes entre ditadura(s) e homossexualidade.

4 Sabemos da existência de termos mais adequados para nomear a multiplicidade de arranjos homoafetivos, tais como LGBT ou LGBTQI+. Contudo, optamos por utilizar o termo 'homossexualidade', concordando com Green e Quinalha (2014), para nâo cometermos anacronismos temporais em relaçáo ao uso de siglas contemporâneas no período ditatorial. 
homossexuais na capital carioca, o romance supracitado sintetiza o conceito da literatura como arquivo da ditadura brasileira, proposto por Figueiredo (2017). Outrossim, nossa leitura também busca agenciar o romance Meu corpo daria um romance (1984) ao conceito de rizoma ${ }^{5}$ (DELEUZE; GUATTARI, 2011), para pensar na constituiçâo de um corpo rizomático, ilustrado pelo comportamento do protagonista da narrativa em contraponto aos organismos conservadores que direcionavam aquele jovem olhares e discursos homofóbicos.

\section{CORPO A CORPO}

Embora Herbert Daniel tenha publicado um considerável número de ensaios e narrativas, o seu nome no âmbito da crítica literária no Brasil e na América Latina é, todavia, desconhecido. Para Pechstein (2015, p. 78), por exemplo, "vale a pena chamar a atençăo para a falta de pesquisa sobre Daniel e sua obra. Há uma ausência notável de estudos sobre a literatura do autor". Partindo dessa lacuna no contexto da crítica brasileira em torno à obra do romancista mineiro, nossas pesquisas se justificam por apresentar uma leitura da obra Meu corpo daria um romance (1984), sob a ótica dos estudos literários e da filosofia contemporânea, com o objetivo de amenizar essa falta. Para além dessa rápida explicaçâo, o romance escrito por Herbert Daniel é representativo por colocar em cena as narrativas de afetividade entre homens gays durante o período ditatorial em nosso país.

Meu corpo daria um romance encontra-se dividido em um total de onze capítulos, com três divisóes. A primeira delas diz respeito ao CORPO A CORPO', que reconstrói os 11 minutos em que o protagonista Daniel entra em um ônibus, na praia de Copacabana, no Rio de Janeiro, após ter beijado o seu namorado. A segunda divisăo corresponde à Matéria, momento em que encontramos histórias sobre a formaçâo do narrador (SILVA, 2014) e, por fim, a terceira divisăo corresponde à Dissertaçâo, na qual o autor surpreende os leitores com uma heterogeneidade de contos que podem ser lidos aleatoriamente.

Para este artigo, nossa análise crítica centra-se na primeira divisăo do livro, ou seja, o CORPO A CORPO, em que Daniel, o protagonista homônimo, encontra-se em um ponto de ônibus, na praia de Copacabana, quando dá sinal para começar uma viagem em que o seu corpo e o seu desejo săo violentados pelos passageiros do transporte público que o olham como diferente, após a troca de um beijo com o seu namorado. Recorremos, entâo, às lembranças de Daniel:

Despedi-me do meu amigo com um beijo na boca, ainda comovido e feliz. Fora tăo bonita aquela conversa toda de bar e intimidades, entrei no ônibus. Ainda acenei

5 O rizoma é um conceito fundamental para interpretar a filosofia de Gilles Deleuze e Félix Guattari. Os autores franceses estabelecem um contraponto com a botânica para exemplificar que um rizoma é um tipo de caule que cresce horizontalmente, criando agenciamentos com o universo. Em oposiçăo, as árvores-raízes săo fixas e suas estruturas crescem verticalmente. Em nosso artigo, associamos o rizoma ao sujeito contemporâneo, caracterizado pelos agenciamentos e pela verticalidade. Os seres tradicionais săo ilustrados pelas árvores-raízes e suas estruturas imóveis e fixas.

6 Decidimos manter o termo CORPO A CORPO em letras maiúsculas, para preservar a grafia utilizada no romance. 
sorrindo para o meu namorado que cambaleava, pálido: as caipirinhas produziram um efeito mau e emocional - e ele gostava de se sentir zonzo e embebedado com o clima que criamos. De tudo resultou que nos despedíamos ali, na madrugada de Copacabana com um beijo - furtivo - na boca (DANIEL, 1984, p. 13).

Embora a troca do beijo entre Daniel e o seu namorado tenha sido potencializada pelo efeito da bebida, percebemos uma transgressáo entre ambos ao arriscar em público uma carícia entre dois homens. É através do olhar panóptico das instituiçôes e da própria sociedade conservadora que o desejo homossexual é reprimido, dado que no plano da normalidade binária, homens năo se relacionam entre iguais. A provocaçâo gerada a partir desse beijo cria um clima de hostilidade vivido pelo protagonista: “Despedi-me, entrei no ônibus e noutra realidade, já năo mais beijo, com olhos que me emparedaram numa observaçăo: bicha!" (DANIEL, 1984, p. 13). As cenas de rechaço à troca de um beijo entre Daniel e seu namorado continuam ao longo das onze paradas que constituem o trajeto entre o ponto inicial e a parada de desembarque:

Vocês comentavam, năo entendi nada, o beijo bicha, escarnecendo o ato que achavam ridículo, meu provável modo de sexualidade. Alteravam a voz numa paródia do que seria uma fragilidade grotesca (feminina? Virgem! Feminina!), ou uma culposa falência masculina (masculina? Mais valia: Macha.); flauteavam: - Vi... a... dô... - bem baixinho, só pra brincar um pouco, sem ruindade, só gozaçăo (DANIEL, 1984, p. 15)

Sabemos que as sociedades atuais estâo enraizadas por um binarismo de gênero. Essa dicotomia operante ao considerar o sexo biológico dos indivíduos delimita o comportamento humano, de modo que, por exemplo, em sociedades tradicionais, năo se espera que um homem, beije outro homem, como acontece na narrativa de Daniel (1984), a qual os passageiros do ônibus chegam a ofender o protagonista em razâo de uma troca de carícia com seu namorado, chamando-o de "viado".

Durante a viagem no transporte público, o corpo de Daniel entra em um jogo de poder e de binarismos de gênero. Ora, Daniel ao trocar um beijo com outro homem desarticula e póe a contrapelo os papéis sociais determinados para homens e mulheres em uma sociedade sexista e preconceituosa. Após o beijo, o personagem questiona os olhares de julgamento que a ele sâo direcionados pelos demais passageiros: "Insuportável é o olhar que te cerca no descampado da calamidade da tua diferença. Insuportável é o olhar da tua inquisiçăo. E demorei o tempo de uma piscadela para me dar conta do estranho que eu era [...]. Por causa de um beijo" (DANIEL, 1984, p. 50).

Estabelecendo uma associaçáo com as ideias dos filósofos contemporâneos Gilles Deleuze e Félix Guattari, o olhar da inquisiçăo narrado por Daniel dentro do ônibus pode ser lido a partir da imagem dos organismos tradicionais e de corpos rizomáticos. Para os estudiosos franceses, um rizoma é absolutamente oposto às radículas fixas de uma árvore. A profundidade do rizoma apresenta-se no plano da horizontalidade, ou seja, "o rizoma, nele mesmo, tem formas muito diversas, desde sua extensâo superficial ramificada em todos os sentidos até suas concreçōes em bulbos e tubérculos" (DELEUZE; GUATTARI, 2011, p. 22). Considerando isso, percebemos inicialmente que os passageiros que estâo no ônibus sâo, de modo geral, muito parecidos:

Muitos passageiros naquele instante deixavam Copacabana que cintilava foscamente na noite morna do seu desejo médio como o de uma classe sem remissáo. Viajavam rumo aos subúrbios homens muitos, muitos homens, quase homem todos; 
masculinos atravessadores da madrugada pouco pecaminosa de véspera de trabalho e intensificaçăo da crise geral da vida (DANIEL, 1984, p. 14).

Os muitos homens que viajavam de volta para suas casas, após um dia de trabalho no Rio de Janeiro, podem ser ilustrados pela ideia de organismo tradicional, pois sua identidade parece ser imóvel, fixa e estanque. É justamente nesse território de binarismo de gênero que as radículas se constituem, se enraízam e se fixam (DELEUZE; GUATTARI, 2011), formando identidades homogêneas, em que práticas homoafetivas, por exemplo, săo questionadas e excluídas dos múltiplos agenciamentos que um rizoma pode conectar. Para mais, a territorialidade espacial da praia de Copacabana ilustra também que os desejos e as homossexualidades nâo tinham espaço naquela regiăo geográfica, marcada pela normalidade de uma "noite morna do seu desejo médio" (DANIEL, 1984, p. 14). Em primeira pessoa, Daniel discorre sobre a diversidade de agenciamentos de sua masculinidade:

Vi-me obrigado - com medo e com raiva - a provar o inviável, porém óbvio: que, sim, estou feliz com o masculino da minha conformaçăo, embora năo me sinta feliz com a conformaçăo estatutária do masculino: que, náo, nada está errado nela em mim, embora haja equívocos nela em todos; que, sim, náo duvido do que estou constituído, embora duvide de uma constituiçăo de máscara; que, náo, náo tenho conflitos com esta masculinidade que até certo ponto escolhi, embora năo tenha escolhido como outros, como talvez, todos aqueles que me policiavam ali (DANIEL, 1984, p. 14).

Os homens que questionaram a masculinidade de Daniel, certamente, atuaram na posiçăo de organismos tradicionais, para os quais 'ser homem' é um conceito fixo, estanque e imutável. Nessa linha de pensamento, o comportamento humano deve reproduzir uma matriz heterossexual, de modo que se espera que o homem - e a mulher - se comporte(m) de formas determinadas. Assim, para os homens que viajavam no mesmo ônibus de Daniel, o conceito de masculinidade, além de estático, năo deve realizar agenciamentos múltiplos com outras dimensóes da sexualidade humana. E, por isto, sob a ótica de Deleuze e Guattari (2011), estamos diante de sujeitos fundamentados em preceitos totalitários, em oposiçăo aos sujeitos que atuam na posiçâo de rizomas. Para os autores franceses a estratificaçăo de uma matriz sexual enviesada por um binarismo de gênero operante causa dor e sofrimento:

Ser rizomorfo é produzir hastes e filamentos que parecem raízes, ou, melhor ainda, que se conectam com elas penetrando no tronco, podendo fazê-las servir a novos e estranhos usos. Estamos cansados da árvore. Năo devemos mais acreditar em árvores, em raízes ou radículas, já sofremos muito. Toda a cultura arborescente é fundada sobre elas, da biologia à linguística. Ao contrário, nada é belo, nada é amoroso, nada é político a năo ser que sejam arbustos subterrâneos e as raízes aéreas, o adventício e o rizoma (DELEUZE; GUATTARI, 2011, p. 34).

Em uma perspectiva deleuze-guattariana, "estamos cansados de árvores" (DELEUZE; GUATTARI, 2011, p. 34) e essa ideia, aparentemente simples, ilustra, além de uma filosofia de/para a vida, os sofrimentos dos seres humanos causados pela rigidez de uma matriz heterossexual, que exclui qualquer possibilidade de agenciamentos múltiplos na sexualidade humana, sobretudo, se esses năo se encontram diretamente relacionados a um binarismo de gênero tradicional, consoante aparece representado na narrativa de Herbert Daniel: 
Foi por causa do beijo no meu amigo: năo há outra razăo para me encararem desse modo, năo há outra evidência em mim. No entanto eles me acusam, os meus companheiros deste transporte público, onde fico sentado rígido e esfacelado. Contaram todos os meus ossos... gemi. - Ih, bicha, náo se faz de vítima, vá. Agora vai querer dar uma de enrustida? Você que anda falando pra todo lado que é sim; que é importante que o homossexual seja "socialmente transparente". Nâo é o que você fala, bicha? Entăo, por que reclama? Quem se mete a avestruz tem que aguentar o ovo. Haja rabo. Que é tăo importante quanto ter peito, bussanha! Ou você vai querer agora que as coisas năo sejam do caralho? (DANIEL, 1984, p. 269).

Marca-se no excerto acima o modo como o protagonista busca reorganizar o próprio corpo, após o beijo, durante a viagem no ônibus. Daniel observa a inexistência de qualquer evidência que localize a sua sexualidade no plano da anormalidade. Portanto, o beijo aparece como a causa principal que justifica os olhares e os discursos dirigidos a ele por sujeitos conservadores. Assim, Daniel senta-se de maneira rígida, ou seja, inflexível, tensa, como tentativa de querer, talvez, 'dar uma de enrustida' (DANIEL, 1984). Por isto, o sofrimento ao qual Deleuze e Guattari (2011) se referem diz respeito à impossibilidade de, em sociedades conservadoras, indivíduos como Daniel vivenciarem práticas homossexuais, sem passar pelo crivo da ignorância, do desrespeito e do preconceito de organismos tradicionais. Se, na contemporaneidade, o desejo entre iguais é, todavia, perseguido ${ }^{7}$ em nome de um binarismo de gênero operante, em épocas de regimes autoritários e antidemocráticos, esse contexto é ainda mais acentuado. Bastaria, para tanto, recordar que no período ditatorial a homossexualidade foi entendida como "parte de um conjunto de desvios sexuais, culturais e morais que trariam o triunfo da subversăo" (GREEN; QUINALHA, 2014, p. 28).

Enquanto estava no ônibus, Daniel conta que: "Havia naqueles olhares algo mais brutal que uma simples crítica ou um banal repúdio. Havia desejo atravancado e fascismo. Algo estritamente político que retorcia as bocas nos sorrisos reflexos [...]" (DANIEL, 1984, p. 84). Nesses regimes autoritários, o fascismo ${ }^{8}$ é uma característica marcante de práticas preconceituosas, e assim, o protagonista se pergunta: "Daniel, você aos trinta e seis anos, publicamente homossexual, está amedrontado e sufocado por um pavor inútil, no meio de pessoas cuja hostilidade você provocou por descuido ou irrealismo" (DANIEL, 1984, p. 84). O protagonista estava incomodado com os olhares que o rodeavam durante a viagem de ônibus e năo entendia o julgamento dos demais passageiros, inclusive, Daniel se culpa, achando que o beijo dado em seu namorado motivava aquela situaçăo de repúdio. Na realidade, a razáo pela qual ele era vítima de homofobia nâo era unicamente o beijo, mas sim o fascismo que estava nos olhares e nos sorrisos daqueles homens que o julgavam e o condenavam.

7 No Brasil do presente, vivemos um movimento de perseguiçấo aos homossexuais. Para fundamentar a nossa afirmaçăo, bastaria citar, por exemplo, algumas das falas do presidente eleito Jair Bolsonaro. Dentre um histórico de frases preconceituosas, Jair Bolsonaro afirmou, em 2011, que: "Ninguém gosta de homossexual. A gente suporta".

8 Diz respeito a um movimento político que nasce na Itália, com Mussolini. O fascismo é, também, uma estrutura de poder que se propaga através do medo e do desrespeito aos direitos humanos. Entretanto, 0 fascismo se desconstrói com amor, coragem, resistência e existência. 
O corpo de Daniel, mesmo desarmado em onze minutos, "como se tivesse sido desarticulado em onze coisas, órgăos, casos, metáforas" (DANIEL, 1984, p. 86) começa a reagir ao fascismo e ao discurso de ódio dos passageiros que o olhavam, o julgavam e o chamavam de 'bicha e viado', utilizando termos depreciativos para a sua masculinidade rizomática:

A vida tem que reagir ao ódio, esta paixáo industriosa. Eu tinha uma vantagem naquela instituiçấo: era homem, quer dizer, tinha uma prática de ira e brutalidade logaritmicamente aprendida como qualidade da macheza real que carregava entre as pernas. Mas todos aqueles outros homens que me submetiam à criteriosa observaçăo do desprezo furioso decretavam minha transmutaçăo corporal. Eu náo era mais um deles e náo era à toa que no vicioso olhar que me encravavam havia tanto desejo sexual. Sim, percebi assustado que me fixavam desejando com paixóes e mais sexuais do que um ódio puramente negativo (DANIEL, 1984, p. 86).

Os organismos tradicionais que dirigiam o olhar para Daniel com preconceito e homofobia buscavam reprimir o seu desejo, retirando-o do convívio social. Contudo, o personagem percebe que essa censura hipócrita dos demais homens aponta para um possível desejo que desponta nos olhos dos outros sujeitos em sua direçăo. Para Daniel (1984, p. 84): "a repressâo nunca é um freio apenas. Caminha com muitos pés, nâo é o sapato que aperta o calo, mas o próprio calo formado, com ou sem calçado, que faz o pé inchado procurar a justa rota de um conforto cego". Com isto, entende-se que a repressâo é um aparato que oprime ao năo conceber a multiplicidade e as diferenças como um aspecto ímpar da vida humana. Mesmo desmascarando os olhares preconceituosos sob a ótica dos desejos, Daniel narra o pânico que o acometeu durante a viagem de ônibus:

Insidiosamente, meus pesquisadores e juízes volteavam sobre a minha anomalia como agouros do branco, cirurgiôes aptos a me castrar até mesmo da felicidade de ter partilhado com meu namorado aqueles instantes afáveis e aquele beijo inadiável (eu o diria, contranatura, inodiável). Um beijo que me valoriza a boca que meus observadores queriam silente e notavam suja. Era um ânus. A bicha que eu era tinha como símbolo um cu, um buraco de abjeçōes, e o resto da conformaçăo física era decorrência imperdoável da analidade (DANIEL, 1984, p. 144)

Com ironia, o narrador chama os passageiros do transporte público de pesquisadores e juízes, os quais julgavam o beijo e a boca de Daniel como um buraco de abjeçóes, caracterizado pela sujeira. Naquele momento, a boca de Daniel tinha como símbolo um cu, o qual "um cu é como esses olhares querem que eu seja, só um cu arrombado" (DANIEL, 1984, p. 145). Nesse momento, a noçâo de Corpo sem Órgâos (DELEUZE e GUATTARI, 2012) aponta para a transfiguraçăo da boca que se assemelha ao ânus porque esta năo seria feita para beijar outro homem. Para Daniel, parte da violência vivida naquele ônibus se justifica pelo fato de que os homossexuais săo semelhantes às mulheres:

Náo pude me reconhecer ali apenas como homossexual - alguém com dada orientaçăo sexual minoritária. Reconhecia-me a partir do desejo de raiva deles, com as mulheres. E me horrorizava por confundir a situaçăo feminina como condiçáo de sujeito passivo. Barra pesada. É barra confundir-se como mulher? Năo: é barra acontecer-se mulher num mundo macho. Poucas saídas. Provoca-se sem intençôes de estimular; basta acontecer e o próprio te-ser é uma provocaçăo que justifica até minuciosos assassinatos (DANIEL, 1984, p. 146). 
Para Deleuze e Guattari (2011, p. 39): "o rizoma, ao contrário, é uma liberaçăo da sexualidade, năo somente em relaçăo à reproduçăo, mas também em relaçăo à genitália", e nesse ponto, fica evidente a caracterizaçâo daqueles homens enquanto organismos tradicionais. Na narrativa, parte dos olhares e preconceitos vividos por Daniel se justificam por uma ideia de sexismo, no qual o próprio Daniel se portou como uma mulher, ao ser carinhoso, afetivo e ao beijar o seu namorado publicamente, afinal de contas: "se aprende, ao estar mulher no reino do falo, a fragilidade, uma circunstância da passividade. A mulher apanha: recebe, dá, leva... Como as bichas. Os passivos tomam no rabo, levam no cu" (DANIEL, 1984, p. 146). Essa é uma visăo de organismo ultraconservador, para os quais homossexuais e mulheres se assemelham porque, ambos, nasceram para apanhar. Daniel se aproxima do final da viagem, refletindo sobre as razóes que o levaram a viver onze minutos de preconceito, de homofobia e de sexismo dentro de um ônibus que cruzava a praia de Copacabana, no Rio de Janeiro:

Foi só dentro do ônibus que entendi que desrespeitara uma regra básica da homossexualidade opressiva do machismo dominante: os atos homossexuais só săo aceitos se travestidos em transas de machos. Gestos duros e simulaçóes de violência săo absolutamente imprescindíveis. Um homem năo toca com carinho outro homem. Dá uma porradinha qualquer, rápida e bruta, uma espécie de orgasmo precoce oficializado (DANIEL, 1984, p. 303).

Portanto, a narrativa escrita por Herbert Daniel (1984), é pertinente para questionar uma matriz heterossexual que, ao delimitar o modo pelo qual homens e mulheres atuarăo em um mundo conservador, exclui qualquer possibilidade que se diferencie do que é tradicionalmente aceito como adequado. Daniel narra que a violência sofrida por ele se justifica porque homossexuais se assemelham às mulheres, e desse modo, encontramos, além do sexismo e da homofobia, o machismo como característica que adjetiva os organismos tradicionais, em contrapelo à ideia de organismos que atuam como rizomas (DELEUZE; GUATTARI, 2011).

\section{ALGUMAS PALAVRAS FINAIS: OU EXISTIR PARA RESISTIR E RESISTIR PARA EXISTIR}

Nesse artigo, realizamos uma breve análise crítica da obra Meu corpo daria um romance, publicada em 1984, pelo escritor mineiro Herbert Daniel. O protagonista homônimo, após beijar o seu namorado em um ponto de ônibus do Rio de Janeiro, inicia uma viagem que dura onze minutos. Durante o trajeto, Daniel vive situaçōes de homofobia, constituídas a partir de discursos e olhares preconceituosos.

Na leitura que propusemos, buscamos aproximar a obra do romancista mineiro ao conceito de rizoma, proposto pelos filósofos franceses Gilles Deleuze e Félix Guattari (2011), para pensar sobre a representaçấo de Daniel enquanto um corpo rizomático. Os demais passageiros do ônibus, ou seja, os que protagonizaram discursos e olhares homofóbicos para com Daniel, sâo caracterizados, por nós, como organismos tradicionais, considerando os pressupostos filosóficos mencionados anteriormente.

O romance escrito por Herbert Daniel faz parte de um conjunto de textos literários que narram e colocam em questăo a temática da ditadura em nosso país. Esses 
romances funcionam como exercícios de memória, como uma obrigaçăo de revisitar a nossa própria história, para que o passado traumático năo volte a ocorrer.

Nesse sentido, se é verdade que as eleiçôes de Jair Bolsonaro representam um momento de barbárie e de fascismo, cabe lembrar que nos anos 1960, quando desligavam as luzes das salas do curso de Ciências Sociais da USP, os alunos davam as máos e diziam uns para os outros: "ninguém solta a mâo de ninguém". Quando a energia era reestabelecida, os estudantes faziam uma espécie de contagem entre si. Muitos deles năo respondiam, pois já nâo estavam mais lá. Por fim, e mesmo correndo o risco de sermos repetitivos, enfatizamos que a leitura de romances que reelaboram a ditadura representa o nosso dever de memória (RICEUR, 2007) com o passado e com as vítimas do autoritarismo no Brasil, como estratégias de resistência e existência. 


\section{REFERÊNCIAS}

DANIEL, H. Meu corpo daria um romance. Rio de Janeiro: Rocco, 1984.

DELEUZE, G; GUATTARI, F. Mil platôs: capitalismo e esquizofrenia. Vol. 1. Traduçâo de Ana Lúcia de Oliveira, Aurélio Guerra Neto e Celia Pinto Costa. Sáo Paulo: Editora 34, 2011.

DELEUZE, G; GUATTARI, F. Mil platôs: capitalismo e esquizofrenia. Vol. 3. Traduçăo de Ana Lúcia de Oliveira, Aurélio Guerra Neto e Celia Pinto Costa. Săo Paulo: Editora 34, 2012.

FIGUEIREDO, E. A literatura como arquivo da ditadura brasileira. Rio de Janeiro: 7Letras, 2007.

FUKS, J. A resistência. Sāo Paulo: Companhia das Letras, 2015.

GREEN, J. N; QUINALHA, R. Ditadura e homossexualidades: repressăo, resistência e busca da verdade. Săo Carlos: EduFSCar, 2014.

KUCINSKI, B. K relato de uma busca. Săo Paulo: CosacNaify, 2011.

KUCINSKI, B. K. Você vai voltar pra mim e outros contos. Sáo Paulo: CosacNaify, 2014.

LÂREDO, S. Olho de boto. Sáo Paulo: Empíreo, 2015.

PECHSTEIN, I. Passagem para o próximo sonho de Herbert Daniel e seu lugar na literatura brasileira pós-regime militar. In: Spanish and Portuguese Review: The American Association of Teachers of Spanish and Portuguese, 2015.

REZENDE, M. V. Outros cantos. Săo Paulo: Editora Alfaguara, 2016.

RICEUR, P. A memória, a história e o esquecimento. Traduçăo de Alain François [et al.]. Campinas, SP: Editora da UNICAMP, 2007.

SILVA, L. S. da. A ficçâo do Eu e do Outro na literatura da homossexualidade. Tese de Doutorado em Letras. Belo Horizonte: Universidade Federal de Minas Gerais, 2016.

SOMMER, D. Ficçōes de fundação: os romances nacionais da América Latina. Traduçăo de Gláucia Renate Gonçalves e Eliana Lourenço de Lima Reis. Belo Horizonte: Editora UFMG, 2004. 